\title{
Influence of Positive Parenting Styles on Self-Regulated Learning in Chinese Adolescents Testing the Mediating Effects of Self-Esteem
}

\author{
Wenbin $\mathrm{Du}^{1}$ (D) $\cdot$ Mengyan Jian ${ }^{2} \cdot$ Fengrui Hua ${ }^{1} \cdot$ Shaojie $\mathbf{Q i}^{1}$
}

Accepted: 9 September 2021 /Published online: 24 September 2021

(c) The Author(s) 2021

\begin{abstract}
The positive parenting styles and the self-esteem of the parents are two factors that affect Self-regulated learning (SRL). Moreover, the variable of self-esteem is influenced by the positive parenting styles. However, previous studies have investigated only the cross-sectional relationship between positive parenting styles and SRL and that between positive parenting styles and self-esteem. This study explored the relationship between positive parenting styles and self-regulated learning in Chinese adolescents and verified the mediating role of self-esteem in this relationship. The study used the panel data of 11801 adolescents (age, 10-15 years) from the 2014 China Family Panel Studies. The main variables were positive parenting styles, selfesteem, and SRL. The results showed that self-esteem plays a partial, but significant, mediating role in the relationship between parents' positive parenting styles and adolescents' SRL ability. This study emphasised that self-esteem is a variable that influences the SRL ability. The more active the parents are, the better the SRL ability of the adolescents is. Positive parenting styles have been proven to promote self-esteem development and can affect the SRL ability of adolescents.
\end{abstract}

Keywords Positive parenting styles $\cdot$ Self-esteem $\cdot$ Self-regulated learning · Mediating effects

Wenbin Du

duwb@swufe.edu.cn

1 Research Institute of Social Development, Southwestern University of Finance and Economics, No. 555, Liutai Road, Wenjiang District, Chengdu 611130, People's Republic of China

2 School of Insurance, Southwestern University of Finance and Economics, Chengdu, People's Republic of China 


\section{Introduction}

\section{Research Background}

In a society built on modern knowledge, people must efficiently collect and utilise the useful information and technologies from a large amount of exponentially grown information. Therefore, structuralising knowledge and actively involving in a strategic learning process is inevitable for people (Chen et al., 2012). In this era of informationisation, learners attach great importance to cultivating an ability to process complex and diverse information and knowledge and understanding how to learn, that is, learning methods. Enabling learners to become the masters of learning and improving and cultivating their learning abilities have become two highly sought-after topics of global education reform in the past decade. Self-regulated learning (SRL) is a new requirement for learners introduced by the education reform. From a broad perspective, SRL is a process, in which learners actively regulate metacognition, motivation, and abehaviour to improve learning results and achieve learning goals. Learners capable of SRL could clarify learning goals, select learning methods, monitor learning processes, and evaluate learning results during acquisition (Zimmerman, 1989). From the ability and skill perspective, SRL refers to goal-oriented activities or abilities such as stimulating, changing, and maintaining in the process of achieving learning goals ( $\mathrm{Lu} \&$ Zhang, 2011). In a narrow sense, SRL refers to learning through which leaners can complete several learning tasks and achieve their required goals by using selfregulated strategies. Numerous theoretical viewpoints on SRL are available, and SRL is perceived as a complex and multifaceted process. This process includes motivational variables (such as self-efficacy and task interest) and self-attribution factors (such as goal setting, adoption of learning strategy, and self-recording) and is designed to assist people to effectively manage and regulate their behaviour (Butler, 1995).

In summary, a positive parenting style and the self-esteem of parents are factors that affect SRL. However, studies have only investigated the cross-sectional relationship between positive parenting styles and SRL and positive parenting styles and self-esteem. Self-esteem is a critical variable used to predict the relationship between positive parenting styles and SRL and to verify the mediating effect of self-esteem on the relationship between positive parenting styles and SRL ability in adolescents. Studies have simply focused on the relationship between and effect of the two variables when discussing these three variables, without specifically addressing the mediating effects of self-esteem. Therefore, this study verified the mediating effect of self-esteem on the relationship between positive parenting styles and SRL ability in Chinese parents and adolescents. The results can help propose an effective intervention approach to improve SRL ability, which is one of the most crucial developmental tasks during adolescence. Because this study focuses on learning abilities of adolescents in their family background, SRL can help predict the specific performance of adolescents in family contexts. 


\section{Literature Review}

\section{SRL and Parenting Style}

SRL abilities are not inherently acquired but cultivated through education and training (Paris \& Newman, 1990), and from this perspective, exploration of factors that influence the improvement of SRL abilities is meaningful. Social cognitive theorists, including Bandura, have stated that for self-regulation, human activities are regulated and developed through the interactions of personal behaviours and environmental factors. This perception does not confine factors affecting an individual's ability to regulate learning to personal factors while emphasising the significance of the environment (Kim \& Lim, 2012). Therefore, understanding the relation between the environment surrounding learners and SRL abilities can help determine better proposals to improve SRL. For a person, the most comfortable environment is the family environment, and the process by which parenting styles affects cognition development in children is considerably vital. Family provides the basic environment of human life and is the environment in which teenagers spend the longest time. Parenting plays a determining role in children's educational and emotional development (Ryan \& Thoms, 2014). In particular, during the transition from childhood to adulthood, adolescents undergo rapid physical and psychological changes, and parenting styles are crucial factors, which cannot be neglected in adolescent education, as they help them adapt to adolescence. Studies investigating the direct effects of parenting styles on SRL ability in Korean middle school students have shown that the more caring and free a parenting style is, the higher the children's SRL ability is (Park \& Jang, 2010). Moreover, the more democratic and positive a parenting style is, the higher the children's SRL ability is (Lim, 2014). Furthermore, studies have explored the relationship between Chinese parenting styles and children's autonomous learning. Chinese fourth grade students and their parents were selected as research objects. The result showed that the parenting style was positively correlated with students' autonomous learning (Huang \& Prochner, 2003).

\section{SRL and Self-Esteem}

Studies have suggested that SRL is related to beliefs in thinking and behavioural skills closely connected to an individual's learning goals (Usher \& Pajares, 2008). Studies on SRL and self-esteem have found that SRL, as a specific form of self-efficacy, is positively related to self-esteem (Klassen et al., 2008; Zuffiano et al., 2013). Moreover, some scholars have found that people with low self-esteem tend to feel negative about their SRL ability to confront challenges (Al-Darmaki, 2012; Phan \& Ngu, 2014). Researchers have always perceived self-esteem and SRL as the components of self; however, studies on the difference between them are considerably limited. The understanding of self by the eastern and western world is influenced by their cultural background. The motivation for self-development is required for self-esteem, according to the western theory of "independent self-construction", in cross-cultural studies, and the "dependent self-construction" of collectivism in the eastern culture primarily aims at maintaining harmony and pursuing integration. 
The meaning of self-esteem is different for various self-constructions. Scholars have surveyed 156 Asian and European American college students to investigate the influence of eastern and western cultural background on people's self-esteem, social values, and SRL efficacy. Their results showed that the self-esteem level of Asian American students can be used to accurately predict the collective self-esteem level of people and that of European students can more likely be used to predict the effectiveness of positive SRL ability (Kim \& Omizo, 2005). A Korean study that used Korean youth as subjects found that the higher a teenager's self-esteem is, the higher their preparation for SRL is (Song, 2006). Another study on the effects of parenting, peer relationships, and SRL ability on the self-esteem of Korean children showed that SRL ability directly affects self-esteem (Woo, 2014). Adolescents' self-esteem is related to SRL ability, and basic self-esteem is required to develop healthy learning habits.

\section{Mediating Role of Self-Esteem between SRL and Parenting Style}

Parenting styles significantly influence personality development, and personality is the main driving factor affecting people's behavioural patterns (Leung \& Lee, 2012). The development of self-esteem, which is a key components of people's self-system, is not only directly related to the mental health of adolescents, but also widely influences adolescents' cognition, motivation, emotions, and social behaviours as a mediating personality variable (Wang et al., 2004). During socialisation, children continue to accept the values of adult society; learn the evaluation from people important in their views based on these values; internalise these evaluation standards, views, and evaluations; internalise praise and condemnation received from important people; and finally, develop their self-esteem (Connelly, 1998). Self-esteem is closely related to parenting styles. Parenting styles highly influence children's intellectual and emotional development and ultimately play a determining role in the quality of parent-child relationships (Becker \& Krug, 1965). The importance of parenting styles was emphasised. The crucial prerequisite for parents to instil positive self-esteem in their children is the exemplary behaviour of parents and behaviours of parents towards their children (Coopersmith, 1967). Many studies have indicated that parenting styles are closely related to children's high self-esteem (Bean \& Northrup, 2009; Bulanda \& Majumdar, 2009). Moreover, studies on Chinese children and adolescents have suggested that active parenting with warm caring and understanding plays a positive role in the development of children's self-esteem (Chen et al., 2007). Children under supportive, caring, and diverse parenting styles have higher self-esteem (Menon et al., 2007). Accepting and loving parenting styles positively influence the development of a high sense of self-esteem (Hurlock, 2001; Kernis et al., 2000). These results indicated that adolescents have increased selfesteem when parents employ positive parenting styles for their children.

In this study, we posited that self-esteem mediated the relationship between parenting style and adolescents' SRL. As discussed in previous studies, self-esteem is a variable influenced by parenting styles that affects SRL. This finding indicated the possibility of self-esteem to be used a mediator variable. Furthermore, by considering the results of the effect of parenting styles' on self-esteem and the effect of 
self-esteem on SRL, this study aims to clarify the relationship among these three variables. In literature, the cases that considered self-esteem a mediating variable for parenting styles and SRL are highly limiting, and independent variables could be different. Referring to studies that considered self-esteem as a mediator, the self-esteem variable can be speculated to have a mediating effect. A study showed intimacy in addition to conflict among Chinese middle school students can be used to predict SRL abilities, and self-esteem partially plays a mediating role (Dong \& Liu, 2019). Another study showed that the self-esteem of preschool teachers in South Korea played a mediating role in children's SRL ability (Choi \& Lee, 2019). Although numerous studies have explored parenting styles and SRL abilities, the structural relationship between self-esteem and SRL abilities has rarely been explored.To fill this gap, this study adopts the perspective of social cognition theory which takes individual and environmental factors in affecting adolescents' learning into account (Ryan \& Thoms, 2014; Zhou et al., 2020).

\section{Research Hypotheses}

The research hypotheses employed in this study are as follows:

Hypothesis 1 The positive parenting style of parents is positively related to adolescents' self-esteem.

Hypothesis 2 Adolescents' self-esteem is positively related to their SRL ability.

Hypothesis 3 The positive parenting a style of parents is positively related to adolescents' SRL ability.

Hypothesis 4 Adolescents' self-esteem plays an intermediary role in parents' positive parenting styles and adolescent's SRL ability.

\section{Methods}

\section{Participants}

This empirical study employed data from 2014 China Family Panel Studies (CFPS). CFPS is a nationally representative, longitudinal tracking survey conducted by the Institute of Social Science Survey of Peking University. Moreover, it aims to reveal the changes in the society, economy, demography, education, and health in China and provides high-quality micro-data for both public policy analysis and academic research. The first wave of CFPS was performed in 2008. The CFPS data of 2014, the thirdwave survey data, were released in June 2016. By using a multistage probability-proportional-to-size sampling technique, approximately 57,000 individuals from 15,000 households in 25 provinces of China were sampled. The data are ideal for this study because the data contain extensive information concerning social capital, depressive symptoms, life satisfaction, socio-demographic characteristics, and health- related behaviour. The data includes four parts: village, family, adult, and children. Because this study mainly examined the SRL ability of adolescents, 10-15 year-old children were selected as subjects. After dropping missing values, 1180 adolescents were 
included in the final analysis. Of the 1180 subjects using the 2014 CPFS data, 800 were male $(67.8 \%)$ and 380 were female $(32.2 \%)$.

\section{Measures}

\section{Dependent Variable: SRL Ability}

In this study, 12 questions comprising panel data from CFPS were employed. They are indicated by a five-point Likert scale, which is divided into five levels: "completely disagree", "disagree", "neither agree nor disagree", 'agree" and "completely agree". Subsequently, they were summed up. A higher score indicated higher SRL efficacy. The reliability factor Cronbach's $\alpha$ was 0.900 .

\section{Independent Variable: Positive Parenting Styles}

The positive parenting style is a combination of parenting ideas, behaviours, and emotions of parents towards children. This combination is relatively stable, does not change with circumstances, and reflects the essence of parent-child interactions (Zhang, 2008). The measurements of this study were revised on the basis of the questionnaire of childrearing without violence. The questionnaire included 14 items. The surveyed adolescents were asked to evaluate the conformity of their parents' behaviours towards them with the description of each item. There were five levels: "never", "rarely", "sometimes", "often" and "always". The higher the score was, the more active, supportive, and proactive the parenting style was. The Cronbach' $\alpha$ of parenting style was 0.726 .

\section{Mediating Variable: Self-Esteem}

Self-esteem is a specific evaluation of an individual, which is obtained after evaluating their characteristics, abilities, and experience, or after a comprehensive evaluation of their entire self to form a complete self-respect (Graeven et al., 1976). Domestically, self-esteem is mostly measured on the Rosenberg scale (1965). Building on this, our study applied the compiled general scale based on a two-dimensional structure model of personal characteristics and emotional experience. This scale comprises 14 items that describe self-recognition. The youths surveyed were asked to evaluate the conformity of their situation with the description of each item. There are five levels: "completely disagree", "disagree", "neither agree nor disagree", "agree" and "completely agree". A score was obtained after summing the results. The higher the total score was, the higher the subject's self-esteem was. Furthermore, the self-esteem variable was measured on the five-point Likert scale with a reliability coefficient (Cronbach' $\alpha$ ) of 0.727 .

\section{Control Variables: Sex and Age}

In this paper, we controlled for the following variables: sex and age. Socio-demographic characteristics included sex and age. Age was a continuous variable. Sex was a binary variable: The male was denoted as " 0 " and the female was " 1 ". 


\section{Data Analyses}

This study used SPSS 21.0 and Amos 18.0 for statistical analyses. Specifically, SEM (Structural equation modelling) was conducted in two steps: measurement and structural models (Kline, 2011). A classic estimator of SEM, maximum likelihood, is based on the assumption that observed variables are continuous and normally distributed. Moreover, Amos 18.0 was used to examine the fitness of the entire model and the relations between of variables. Subsequently, to understand the relationship between positive parenting styles, self-esteem and SRL, a path analysis was performed. $\chi^{2}$ verification and four fitness indexes, namely TLI, CFI, RMSEA, and SRMR, were used for model evaluation. To confirm the mediating effect of the indirect path, the bootstrap method was used. The following criteria were used to determine a suitable model fit: RMSEA and SRMR values of $<0.05$ and TLI and CFI values of $>0.90$. All statistical tests were two-sided $(p=0.05)$. Bootstrapping was conducted to test the statistical significance of the direct, indirect and total effects of the model.

\section{Results}

\section{Descriptive Results}

Table 1 presents the socio-demographic characteristics of respondents. The respondents' average age was $10.848 \pm 1.079$ years; among 1180 subjects, 800 were male $(67.8 \%)$ and 380 were female $(32.2 \%)$.

\section{Descriptive Statistics of Key Variables and Their Correlation}

Key variables were the positive parenting styles of Chinese parents and teenagers' self-esteem and SRL. All variables were composed of latent variables. Before the structural equation model analysis, the mean, standard deviation, skewness, and kurtosis of each variable were examined. Correlation coefficients between measured variables were obtained, and Table 2 presents the results. The average and standard deviation $(S D)$ of the positive parenting styles measured using the 14 questions were 3.889 and 0.706 , respectively, on the five-point scale. The average self-esteem measured using the 14 questions was $3.970(S D=0.786)$. The 12 questions on SRL were measured on the five-point scale. The average value of SRL was 3.943

Table 1 Characteristics of the study sample $(n=1180)$

\begin{tabular}{lll}
\hline Variable & $\mathrm{N}(\%)$ & $\mathrm{M}(\mathrm{SD})$ \\
\hline Sex & & \\
Male & $380(32.2)$ & \\
Female & $800(67.8)$ & $10.848(1.079)$ \\
Age & - & \\
\hline
\end{tabular}


$(S D=0.784)$. The skewness range was -0.571 to -1.045 , and the kurtosis range was $0.417-1.887$. Generally, when the skewness and kurtosis are $<3$ and $<8$, respectively, in absolute value, normality is considered as satisfied (Kline, 2011). Table 2 shows that because the skewness and kurtosis of each variable in this study does not exceed 3 and 8, respectively, the distribution normality is considered satisfied. Correlation coefficients of the measured variables were distributed between 0.479 and 0.530 . The result of the correlation analysis indicated that all variables are statistically significant and correlated.

\section{Analysis of Measurement Model}

\section{Question Reliability, Composition Reliability, Convergence Validity, and Discriminant Validity Analyses}

Because the concepts used in this study were measured to be multiple, the reliability and feasibility of measurement items were analysed. Table 2 shows that the suggested value of squared multiple correlations is $>0.5$. The $C R$ value is a combination of all measurement variables and represents the internal consistency of a dimensional index, which is equivalent to Cronbach' $\alpha$. The higher is the $C R$ value, the higher is the internal consistency. A composition reliability of 0.7 is the threshold for the acceptable reliability (Hair et al., 1998). The average variance extracted (AVE) is the averaged ratio of the explanatory power of latent variables to measured

Table 2 Descriptive statistics of major variables, correlation analysis between variables, and reliability and validity test of measurement items

\begin{tabular}{|c|c|c|c|c|c|c|c|c|c|}
\hline Dimension & Item & U.Std & SE & Z & $\mathrm{P}$ & Std & SMC & $\mathrm{CR}$ & AVE \\
\hline \multirow[t]{3}{*}{ PBI } & PBI1 & 1.000 & & & & 0.655 & 0.429 & 0.729 & 0.474 \\
\hline & PBI2 & 1.096 & 0.085 & 12.875 & $* * *$ & 0.723 & 0.523 & & \\
\hline & PBI3 & 1.120 & 0.089 & 12.532 & $* * *$ & 0.685 & 0.469 & & \\
\hline \multirow[t]{3}{*}{ SRL } & SRL1 & 1.000 & & & & 0.846 & 0.716 & 0.903 & 0.756 \\
\hline & SRL2 & 1.092 & 0.039 & 27.893 & $* * *$ & 0.924 & 0.854 & & \\
\hline & SRL3 & 0.951 & 0.038 & 24.815 & $* * *$ & 0.836 & 0.699 & & \\
\hline \multirow[t]{2}{*}{ RSES } & RSES1 & 1.000 & & & & 0.732 & 0.536 & 0.728 & 0.572 \\
\hline & RSES2 & 1.049 & 0.079 & 13.228 & $* * *$ & 0.780 & 0.608 & & \\
\hline Variables & $\begin{array}{l}\text { Parenting } \\
\text { style (PBI) }\end{array}$ & $\begin{array}{l}\text { Self-esteem } \\
\text { (RSES) }\end{array}$ & $\begin{array}{l}\text { Self-regu- } \\
\text { lated learn- } \\
\text { ing (SRL) }\end{array}$ & & & & & & \\
\hline PBI & 1 & & & & & & & & \\
\hline RSES & $.479^{* *}$ & 1 & & & & & & & \\
\hline SRL & $.530^{* *}$ & $.521^{* *}$ & 1 & & & & & & \\
\hline Mean (SD) & $3.889(0.706)$ & $3.970(0.786)$ & $3.943(0.784)$ & & & & & & \\
\hline Skewness & -.571 & -1.045 & -.622 & & & & & & \\
\hline Kurtosis & .417 & 1.887 & .538 & & & & & & \\
\hline
\end{tabular}

$* p<.05, * * p<.01, * * * p<.001$ 
Table 3 Test of latent variable difference validity

\begin{tabular}{lllll}
\hline Dimension & AVE & RSES & SCS & PBI \\
\hline RSES & 0.729 & 0.854 & & \\
SRL & 0.903 & 0.628 & 0.950 & \\
PBI & 0.728 & 0.657 & 0.627 & 0.853 \\
\hline
\end{tabular}

Table 4 Structural model fit

\begin{tabular}{lccccc}
\hline$\chi^{2}$ & $\mathrm{df}$ & TLI & CFI & RMSEA & SRMR \\
\hline 45.718 & 17 & .978 & .987 & .054 & .025 \\
\hline
\end{tabular}

variables. The higher is the AVE, the higher is the convergence validity of dimensions. Fornell and Larcker (1981) suggested that AVE should be $>0.5$, and 0.36-0.5 is the threshold for an acceptable AVE. The reliability of the questions satisfies these requirements (Table 2).

The results presented in Table 3 indicate that the root value of AVE for the dimensions is higher than their correlations with other dimensions. The aforementioned dimensions have good discriminant validity. Based on the aforementioned analysis, the processed data were modelled, and the reliability and validity of the potential variables of the research model were tested (Table 2). The internal consistency, reliability, and validity of the variables meet the corresponding index requirements, which indicated that potential variables have high internal consistency and good reliability and validity.

\section{Structural Model Results}

\section{Fitness of Structural Model}

Table 4 shows that the fitness of the structural model for the three latent variables was verified, and the $\chi 2$ value was $45.718(d f=17 ; p=0.000)$, which is statistically significant at the $0.1 \%$ level. TLI, CFI, SRMR, and RMSEA were used to evaluate the fitness. Considering the number of observations and the simplicity of the model, TLI and CFI values were 0.978 and 0.987 , respectively. A value of 0.90 or higher was obtained, which indicated a suitable fit. SRMR and RMESA received a score of 0.025 and 0.054 , respectively, which was considered acceptable.

\section{Research Model Path Analysis Results}

Table 5 and Fig. 1 show that all path coefficients are statistically significant. Specifically, the higher is the active parenting style, the higher is the level of self-esteem $(B=00.657 ; p<0.001)$. Additionally, self-esteem helps predict SRL $(B=0.380$; $p<0.001)$. Higher self-esteem indicates higher SRL ability. Positive parenting styles 
Table 5 Research model path analysis

\begin{tabular}{lllllll}
\hline Parameter & & Estimate & SE & \multicolumn{1}{l}{ CR } & P & Std estimate \\
\hline PBI $\rightarrow$ & RSES & 0.764 & 0.055 & 13.913 & 0.000 & 0.657 \\
PBI $\rightarrow$ & SRL & 0.494 & 0.065 & 7.663 & 0.000 & 0.378 \\
RSES $\rightarrow$ & SRL & 0.427 & 0.055 & 7.807 & 0.000 & 0.380 \\
\hline
\end{tabular}

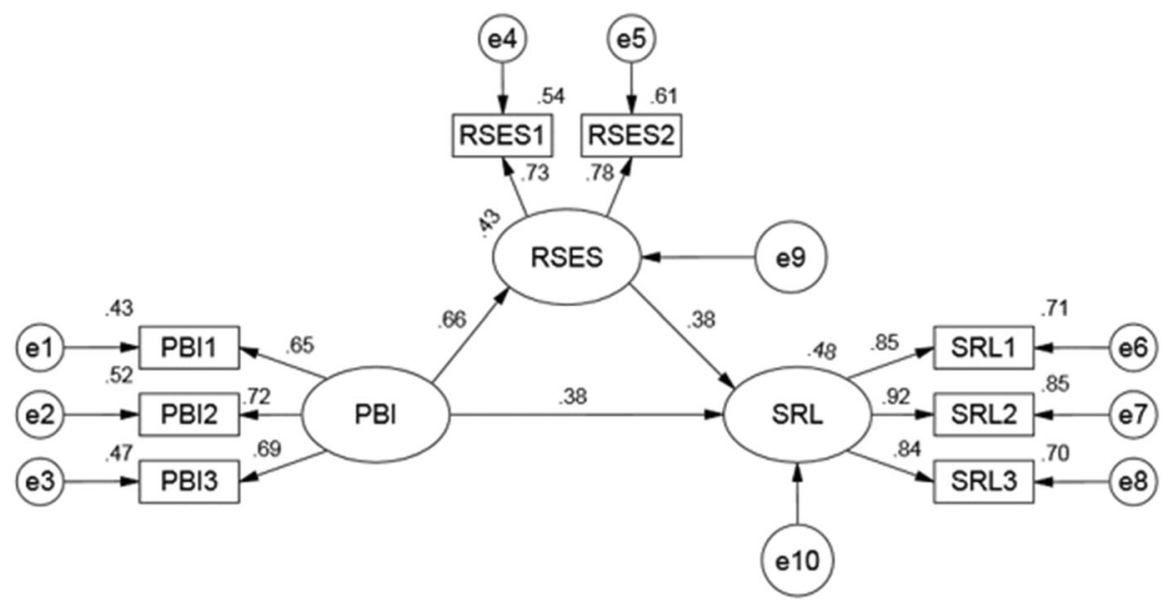

Fig. 1 Research model. PBI parental bonding instrument; RSES rosenberg self-esteem Scale; SRL selfregulated learning

significantly influence adolescents' SRL ability $(B=00.378 ; p<0.001)$. Better parenting styles lead to higher SRL abilities of adolescents.

\section{Mediating Effect}

To verify the mediating effect, bootstrapping, a methods used to verify the mediating effect, was conducted. The main principle of bootstrap is to set a sampling pool as the total of the research sample; an observation is drawn from the research sample and subsequently is returned to the pool and then observation drawing is continued until an appropriate number of samples is obtained. Finally, the average value of sample parameters obtained from each sampling is used as the estimate. Compared with the sample step analysis method, the bootstrap method can obtain more accurate parameter estimates, thereby making the mediating effect results more accurate and ensuring the reliability of final conclusions (Shrout \& Bolger, 2002). Therefore, this study applied the bootstrap method to examine the mediating hypothesis in the model. Table 6 presents the results of the direct, indirect, and total effects of the variables included in the structural model. 
Specifically, the total influence of positive parenting styles on SRL was 0.821 (0.627), among which the direct and indirect effects were $0.494(0.378)$ and 0.327 (0.250), respectively. The indirect confidence interval was $0.222-0.455$, which does not include " 0 ", indicating that the mediating effect is statistically significant at the significance level of $1 \%$. The direct effect confidence interval was $0.323-0.658$, which does not include " 0 ", indicating the presence of the direct effect. Therefore, the positive parenting style exhibits a partial mediating effect on the self-regulation of adolescents.

\section{Discussion}

\section{Summary}

This study presents the context of child development. The study was conducted by considering the theoretical background that a family's environmental factors, especially the positive parenting styles and self-esteem, affect a child's SRL. This study investigated positive parenting styles by using self-esteem as a mediating variable to study the path of and effect on SRL, and a research model was established. The structural equation model was used to analyse a panel data of 1180 adolescents aged 10-15 years from 2014 CFPS. This analysis was conducted to verify that the positive parenting styles of Chinese parents affect adolescents' SRL and that adolescents' self-esteem plays a mediating role.

Among path coefficients showing the relationship between variables, the following paths were statistically significant: the effect of adolescents' perception of their parents' positive parenting style on self-esteem, the effect of self-esteem on the teenager's SRL and the effect of positive parenting styles on SRL. By employing the bootstrap method to the model, a significant correlation between positive parenting styles and adolescents' self-esteem was found, and self-esteem plays a partial mediating role. The model fit is suitable, and the direct path is meaningful. Furthermore, the results are consistent with those of previous studies. Positive parenting styles play a positive role in adolescents' SRL ability (Huang \& Prochner, 2003; Lim, 2014; Park \& Jang, 2010). The higher is the adolescents' cognition of their parents' parenting styles, the higher is their SRL ability and the higher is the ability to independently regulate learning. The results are consistent with the previous results that positive parenting styles affect adolescents' self-esteem (Bean \& Northrup, 2009;

Table 6 Mediating effects

\begin{tabular}{|c|c|c|c|c|}
\hline \multicolumn{2}{|l|}{$\mathrm{PBI} \rightarrow \mathrm{RSES} \rightarrow \mathrm{SCS}$} & \multicolumn{2}{|c|}{$\begin{array}{l}\text { Bootstrapping } \\
\text { bias corrected } \\
95 \% \text { CI }\end{array}$} & \multirow[b]{2}{*}{ Std estimate } \\
\hline Variable relationship & Estimate & Lower & Upper & \\
\hline Direct effect & 0.494 & 0.323 & 0.658 & 0.378 \\
\hline Indirect effect & 0.327 & 0.222 & 0.455 & 0.250 \\
\hline Total effect & 0.821 & 0.688 & 0.964 & 0.627 \\
\hline
\end{tabular}


Bulanda \& Majumdar, 2009; Chen et al., 2007; Hurlock, 2001; Kernis et al., 2000; Menon et al., 2007) and self-esteem affects SRL of adolescents (Klassen et al., 2008; Song, 2006; Woo, 2014; Zuffiano et al., 2013).

The results of the mediating effect indicated that adolescents' self-esteem plays a mediating role in the effect of perceived positiveness of parenting styles on SRL. Positive parenting styles not only directly affect children's SRL but also can influence SRL through the mediating role of self-esteem. Specifically, positive parenting styles can help directly predict children's SRL and can improve the SRL ability by improving self-esteem. This result is consistent with that of a study (Lim, 2014), which showed that the parents with positive parenting styles have moderate control over their children, that is while controlling their children, parents give their children democratic rights to express their opinions and warm support, which is conducive to fostering psychological autonomy and thus to improving self-learning ability. Therefore, positive parenting styles have a predictive effect directly on adolescents' SRL. Positive parenting can make children aware about parents' respect and emotional support towards them, which helps children form positive self-attitudes and evaluations and improve their self-esteem. Positive parenting styles can better meet the requirements of children and help establish a healthy relationship with the children. This style makes children establish a positive self-image, that is, high self-esteem and enables children to form the conception that "the world is safe", which is beneficial for children to cultivate the quality of positive exploration during interpersonal communication in the future.

Positive active parenting styles such as parenting with democracy, tolerance, and encouragement increase children's SRL ability. In the family environment, children can effectively adjust self-esteem and self-evaluation ability. Moreover, this study verified the effect of positive parenting styles on children's SRL ability, and the significance of the mediating effect of self-esteem. The results showed that the positive parenting style with a warm, understanding, and democratic approach not only has a positive effect on SRL ability but also strengthens children's self-esteem and eventually improve their SRL ability (Park \& Jang, 2010). Therefore, self-esteem is a variable affecting SRL ability. The more positive is the parenting style, the better is the adolescent's autonomous learning ability. In reality, studies have proved that positive parenting styles with warm understanding and democratic care improve self-esteem development.

The results indicated that positive parenting styles are positively correlated with adolescents' self-esteem. The positive effects of parenting styles on adolescents' psychosocial adaptation and mental health development were confirmed in a study (Lai et al., 2014). These effects occur because active parenting often provides children sufficient warmth and support and guides and educates children in a nurturing manner. When a family makes major decisions, the parents can be attentive and respect the views of children, so that the children can participate in family affairs in a democratic manner. This is conducive to the cultivation of children's independence and autonomy, which facilitate adaptation and helps form a positive concept of self (Liu et al., 2012). The positive effects of parenting styles on adolescents' psychosocial adaptation and mental health development were confirmed by another study (Lai et al., 2014). SRL, as a specific form of self-efficacy, is significantly positively 
related to self-esteem (Klassen et al., 2008; Song, 2006; Woo, 2014; Zuffiano et al., 2013).

\section{Implications}

\section{Academic Implications}

There are several theoretical and practical implications of the present findings. First, the study provides important insights on the direct effect and mediating mechanisms of parents' positive parenting styles on Chinese adolescents' SRL ability. This study investigated variables that affect the improvement of SRL ability in adolescents during the crucial stage of developing learning ability and primarily focused on parenting styles and self-esteem. Although numerous studies have explored parenting styles and SRL abilities, the structural relationship between self-esteem and SRL abilities has rarely been explored. Before this study, for the relationship between positive parenting styles and SRL ability, self-esteem was integrated into a single model as a mediating effect and the structural relationship was analysed. The innovative perspective highlighted the significance of this study. Second, this study found that positive parenting attitudes can affect adolescents' self-esteem, and selfesteem can influence SRL ability. This finding supports that of the study of Ryan and Thoms (2014), which was based on social cognition theory, thus emphasising the effect of parenting on children's learning and emotions. Development acts as a major determinant. Park et al. (2010) reported that SRL, as a specific form of selfefficacy, is related to self-esteem. Moreover, this study found that self-esteem plays a partial mediating role between positive parenting attitude and SRL ability. Positive parenting attitude can indirectly affect the SRL ability of adolescents by improving their self-esteem.

\section{Practical Implications}

In addition, this study has the following practical implications. First, the variables that affect adolescents' SRL ability the most are self-esteem and positive parenting styles. In particular, adolescence is a period of sensitive changes; thus, to perceiving the transition and forming a new parent-child relationship are necessary for the parents. If internal and external changes in children during adolescence are not understood, conflicts can arise and parents can experience considerable psychological difficulties (Leary \& MacDonald, 2003; Leung \& Fung, 2021). Therefore, in the context of psychological contradictions and dramatic changes, providing positive support to adolescents and children through positive parenting methods, providing various related parental education programs, and developing courses to improve adolescents' self-esteem can help enhance SRL. Second, attention should be paid to family education, and parenting styles should be improved. In traditional Chinese families, parents set high goals for their children. If children are often incompetent, the parents will have a mentality of "hate iron is not steel" and produce negative mental state, or parents will adopt negative parenting styles instead of positive 
parenting styles. This mental state or negative parenting styles will also have a negative impact on adolescents' academic performance, mental health, and subjective well-being (Leung \& Shek, 2020; Shek et al., 2018, 2019). Parents should care for and love children more to create a harmonious and democratic atmosphere. When a child encounters setbacks or failures, parents should comfort and advise them, rather than scolding and criticising (Coopersmith, 1967). Adolescents undergo major physiological and psychological changes. Parents should provide adolescents more care, love, and warmth and support them with positive guidance, thus improving their self-confidence and self-esteem. Schools can conduct thematic activities to help adolescents understand themselves correctly and go through this adolescence stage smoothly. Finally, parents should guide teenagers to develop correct self-awareness. Self-esteem is a sense of self-worth based on external factors. Vulnerable people experience more stress, anger, and interpersonal problems (Crocker \& Park, 2004). Therefore, establishing a correct approach for self-evaluation is necessary for teenagers. Adolescents should pay attention to their inherent qualities, accurately understand themselves, and perceive people's opinion objectively. Finally, developing multiple projects to enhance self-esteem is a crucial approach for improving adolescents' SRL ability. These projects can be of considerable significance for cultivating children's self-esteem and further promoting their autonomous learning and development.

\section{Limitations and Future Research}

First, data on positive parenting styles of fathers and mothers were analysed together; thus, the effect of parenting styles based on parents' gender could not be differentiated. In the future study, the influence of fathers' and mothers' parenting styles on adolescents' SRL ability must be explored separately.

Second, because this study only analysed the data for 10-15-year-old adolescents, general ability is limited to young people of other ages. In future studies, whether the results are explanatory for adolescents of all ages must be determined.

Finally, the limitations of this study were affected by the cross-sectional data, including the limitation of micro data, serious data loss, and short time dimensions. No in-depth analysis and discussion are available on some analysis results. These problems are worthy of being addressed in future studies.

\section{Declarations}

Conflict of interest The authors declare that they have no conflict of interest.

Open Access This article is licensed under a Creative Commons Attribution 4.0 International License, which permits use, sharing, adaptation, distribution and reproduction in any medium or format, as long as you give appropriate credit to the original author(s) and the source, provide a link to the Creative Commons licence, and indicate if changes were made. The images or other third party material in this article are included in the article's Creative Commons licence, unless indicated otherwise in a credit line to the material. If material is not included in the article's Creative Commons licence and your intended use is not permitted by statutory regulation or exceeds the permitted use, you will need to obtain permission 
directly from the copyright holder. To view a copy of this licence, visit http://creativecommons.org/licen ses/by/4.0/.

\section{References}

Al-Darmaki, F. R. (2012). Relationships between career counseling attitudes and self-esteem and selfefficacy among emirati university students. Journal of Career Development, 39(2), 143-161. https:// doi.org/10.1177/0894845310380046

Bean, R. A., \& Northrup, J. C. (2009). Parental psychological control, psychological autonomy, and acceptance as predictors of self-esteem in latino adolescents. Journal of Family Issues, 30(11), 1486-1504. https://doi.org/10.1177/0192513X09339149

Becker, W. C., \& Krug, R. S. (1965). The parent attitude research instrument-A research review. Child Development, 36, 329-365. https://doi.org/10.1111/j.1467-8624.1965.tb05302.x

Bulanda, R. E., \& Majumdar, D. (2009). Perceived parent-child relations and adolescent self-esteem. Journal of Child and Family Studies, 18(2), 203-212. https://doi.org/10.1007/s10826-008-9220-3

Butler, D. L. (1995). Promoting strategic learning by postsecondary students with learning disabilities. Journal of Learning Disabilities, 28(3), 170-190. https://doi.org/10.1177/0022219495 02800306

Chen, C., Ni, H., \& Yang, J. (2007). The influence of the temperament of senior primary school children on the parenting style. Journal of Nanjing Normal University: Social Science Edition, 03, 109-115.

Chen, X., Zhang, G., Chen, H., \& Li, D. (2012). Performance on delay tasks in early childhood predicted socioemotional and school adjustment nine years later: A longitudinal study in Chinese children. International Perspectives in Psychology: Research, Practice, Consultation, 1(1), 3-14.

Choi, H. J., \& Lee, G. H. (2019). The effect of self-esteem and self-regulated learning ability of preservice early childhood teachers on teacher efficacy. The Journal of Korea Open Association for Early Childhood Education, 24(2), 169-188. https://doi.org/10.1002/0471264385

Connelly, C. D. (1998). Hopefulness, self-esteem, and perceived social support among pregnant and nonpregnant adolescents. Western Journal of Nursing Research, 20(2), 195-209. https://doi.org/ 10.1177/019394599802000205

Coopersmith, S. (1967). The antecedents of Self-esteem. W. H. Freeman.

Crocker, J., \& Park, L. E. (2004). The costly pursuit of self-esteem. Psychological Bulletin, 130(3), 392-414. https://doi.org/10.1037/0033-2909.130.3.392

Dong, Y. H., \& Liu, D. (2019). The effect of sibling relationship on the academic self-efficacy of junior school students: The mediating role of self-esteem and the moderating role of birth order\%. Basic Education, 16(003), 94-100.

Fornell, C., \& Larcker, D. F. (1981). Structural equation models with unobservable variables and measurement error: Algebra and statistics. Journal of Marketing Research, 18(3), 382-388. https://doi.org/10.2307/3150980

Graeven, D. B., Webster, M., Sobieszek, B., Wells, L. E., \& Marwell, G. (1976). Self-esteem: Its conceptualization and measurement. Contemporary Sociology, 5(6), 822.

Hair, J. F., Tatham, R. L., Anderson, R. E., \& Black, W. (1998). Multivariate data analysis. Technometrics, 30(1), 130-131.

Huang, J., \& Prochner, L. (2003). Chinese parenting styles and children's self-regulated learning. Journal of Research in Childhood Education, 18(3), 227-238.

Hurlock, E. B. (2001). Developmental psychology. Tata McGraw-Hill Education.

Kernis, M. H., Brown, A. C., \& Brody, G. H. (2000). Fragile self-esteem in children and its associations with perceived patterns of parent-child communication. Journal of Personality, 68(2), 225-252. https://doi.org/10.1111/1467-6494.00096

Kim, B. S. K., \& Omizo, M. M. (2005). Asian and European American cultural values, collective self-esteem, acculturative stress, cognitive flexibility, and general self-efficacy among Asian American college students. Journal of Counseling Psychology, 52(3), 412-419. https://doi.org/ 10.1037/0022-0167.52.3.412

Kim, Y. M., \& Lim, S. K. (2012). Structural model of democratic parenting style, ego-resilience, cell phone dependency. National Youth Policy Institute, 23(2), 273-299. 
Klassen, R. M., Krawchuk, L. L., \& Rajani, S. (2008). Academic procrastination of undergraduates: Low self-efficacy to self-regulate predicts higher levels of procrastination. Contemporary Educational Psychology, 33(4), 931. https://doi.org/10.1016/j.cedpsych.2007.07.001

Kline, R. B. (2011). Principles and practice of structural equation modeling (3rd ed.). The Guilford Press.

Lai, Y. C., Ye, Y., \& Cheng, Z. H. (2014). Relationship between parenting style and interpersonal sensitivity of middle school students. Chinese Journal of Clinical Psychology, 22(5), 908-910.

Leary, M. R., \& Macdonald, G. (2003). Individual differences in self-esteem: A review and theoretical integration. The Guilford Press.

Leung, J. T. Y., \& Fung, A. L. (2021). Editorial: Special issue on quality of life among children and adolescents in Chinese societies. Applied Research Quality Life. https://doi.org/10.1007/ s11482-021-09915-9

Leung, J. T. Y., \& Shek, D. T. L. (2020). Parental sacrifice, filial piety and adolescent life satisfaction in chinese families experiencing economic disadvantage. Applied Research in Quality of Life, 15, 259-272. https://doi.org/10.1007/s11482-018-9678-0

Leung, L., \& Lee, P. S. N. (2012). The influences of information literacy, internet addiction and parenting styles on internet risks. New Media and Society, 14(1), 117-136. https://doi.org/10.1177/ 1461444811410406

Lim, S. A. (2014). The effects democratic and non-democratic parenting style on child's self-regulated learning ability, school adjustability, and academic achievement of elementary school children (using SEM). The Journal of Elementary Education, 27(2), 73-93. https://doi.org/10.6115/ fer. 2018.034

Liu, W. J., Xu, Z. X., \& Zou, H. (2012). The influence of parenting style on adolescents' social adaptation: The moderating effect of personality type. Psychological Development and Education, 28(6), 625-633.

Lu, H. D., \& Zhang, L. (2011). Research progress and trend of self -regulated learning. Journal of Northeast Normal University, 6, 145-149.

Menon, M., Tobin, D. D., Corby, B. C., Menon, M., \& Perry, D. G. (2007). The developmental costs of high self-esteem for antisocial children. Child Development, 78(6), 1627-1639. https://doi. org/10.1111/j.1467-8624.2007.01089.x

Paris, S. G., \& Newman, R. S. (1990). Development aspects of self-regulated learning. Educational Psychologist, 25(1), 87-102. https://doi.org/10.1207/s15326985ep2501_7

Park, J. K., \& Jang, S. H. (2010). The relationship between parents parenting style and self-directed learning readiness in middle school students. Journal of Learner-Centered Curriculum and Instruction, 10(1), 107-126.

Phan, H. P., \& Ngu, B. H. (2014). Interrelations between self-esteem and personal self-efficacy in educational contexts: An empirical study. International Journal of Applied Psychology, 4(3), 108-120. https://doi.org/10.5923/j.ijap.20140403.05

Rosenberg, M. (1965). Society and the adolescent self-image. Princeton University Press

Ryan, D. S., \& Thoms, J. M. (2014). Parenting style transitions and delinguency. Youth and Society, 46(2), 228-254.

Shek, D. T. L., Zhu, X., \& Dou, D. (2019). Influence of family processes on internet addiction among late adolescents in Hong Kong. Frontiers in Psychiatry, 10, 113. https://doi.org/10.3389/fpsyt. 2019.00113

Shek, D. T. L., Zhu, X., \& Ma, C. M. S. (2018). The influence of parental control and parent-child relational qualities on adolescent internet addiction: A 3-year longitudinal study in Hong Kong. Frontiers in Psychology. https://doi.org/10.3389/fpsyg.2018.00642

Shrout, P. E., \& Bolger, N. (2002). Mediation in experimental and nonexperimental studies: New procedures and recommendations. Psychological Methods, 7, 422-445. https://doi.org/10.1037/ 1082-989X.7.4.422

Song, K. A. (2006). A study on Influence of Self-esteem and Self-determination motivation on selfdirected learning. Journal of Early Childhood Education and Educare Administration, 10(3), $177-202$.

Usher, E. L., \& Pajares, F. (2008). Self-efficacy for self-regulated learning-A validation study. Educational and Psychological Measurement, 68, 443-463. https://doi.org/10.1177/0013164407 308475

Wang, X., Ruan, X., \& Ruan, J. (2004). The relationship between parenting style and self-esteem of college students. Chinese Journal of Clinical Psychology, 12(3), 309-310. 
Woo, S. J. (2014). The effects of undesirable parenting behavior, children's peer relationship and selfregulated learning on children's self-esteem. Korean Journal of Human Ecology, 23(5), 759771. https://doi.org/10.5934/kjhe.2014.23.5.759

Zhang, W. X. (2008). Higher education psychology. Shandong University Press.

Zhou, Q., Guo, S., \& Lu, H. J. (2020). Well-being and health of children in rural china: The roles of parental absence, economic status, and neighborhood environment. Applied Research in Quality of Life. https://doi.org/10.1007/s11482-020-09859-6

Zimmerman, B. J. (1989). A social cognitive view of self-regulated academic learning. Journal of Educational Psychology, 81(3), 329-339. https://doi.org/10.1037/0022-0663.81.3.329

Zuffiano, A., Alessandri, G., Gerbino, M., Kanacri, B.P.-L., Di Giunta, L., Milioni, M., \& Caprara, G. V. (2013). Academic achievement: The unique contribution of self-efficacy beliefs in self-regulated learning beyond intelligence, personality traits, and self-esteem. Learning and Individual Differences, 23, 158-162.

Publisher's Note Springer Nature remains neutral with regard to jurisdictional claims in published maps and institutional affiliations. 